\title{
Junction Properties of Metal/Polypyrrole Schottky Barriers
}

\author{
P. SYED ABTHAGIR, R. SARASWATHI \\ Department of Materials Science, Madurai Kamaraj University, Madurai 625 021, Tamilnadu, India
}

Received 1 June 2000; accepted 6 October 2000

\begin{abstract}
Schottky barriers of the type Au/polypyrrole/Al (or In) were made in sandwich configuration. The conductivity of polypyrrole was tuned to be on the order of $10^{-3}$ $\mathrm{ohm}^{-1} \mathrm{~cm}^{-1}$ by its electrodeposition from a novel ambient temperature ternary eutectic melt consisting of acetamide, urea, and ammonium nitrate. The rectification characteristics were obtained from the current-voltage and capacitance-voltage measurements at room temperature. The analysis of data using thermionic emission theory gave improved values for the junction parameters of ideality factor, reverse saturation current, rectification ratio, and barrier potential when compared to the previously reported values for this polymer. Between $\mathrm{Al}$ and In metals used for the junction formation, the diode formed with $\mathrm{Al}$ metal is found to show better performance. The energy gap and work function of polypyrrole were also estimated. () $2001 \mathrm{John}$ Wiley \& Sons, Inc. J Appl Polym Sci 81: 2127-2135, 2001
\end{abstract}

Key words: polypyrrole; Schottky diode; junction properties; ternary eutectic melt

\section{INTRODUCTION}

During the last two decades, there has been considerable interest to replace conventional inorganic semiconductors with organic materials in electronic and optical devices. ${ }^{1}$ Toward this goal, attempts have been made to use conducting organic-conjugated polymers as active materials in the fabrication of junction devices. ${ }^{2,3}$ Schottky barriers based on the junctions of a semiconducting polymer and a metal were investigated as photovoltaic energy converters. ${ }^{4}$ In particular, electrical properties of heterojunctions and Schottky barriers devised with thin films of polyacetylene, polythiophene, polyparaphenylene, polyaniline, polypyrrole $(\mathrm{PPy})$, and poly $(N$-methylpyrrole) were reported.$^{5-10}$ Although most of these junctions showed rectifying behavior, the device

Correspondence to: R. Saraswathi.

Contract grant sponsor: Council of Scientific and Industrial Research.

Journal of Applied Polymer Science, Vol. 81, 2127-2135 (2001)

(C) 2001 John Wiley \& Sons, Inc. parameters were far from ideal diode characteristics. The diode quality factor (or ideality factor $n$ ) was reported to vary from 2 to 11 . However, the device performance can be improved largely by suitably designing the synthesis of the polymer film. Often, electrochemical method, LangmuirBlodgett technique, and vacuum deposition have been used to prepare thin polymer films for such applications. ${ }^{11,12}$ Also, the conductivity of the polymer is of major importance in constructing a Schottky barrier. A low doping of the polymer is associated with a low number of charge carriers, leading to an extended depletion layer in the junction. On the other hand, high-charge carrier densities in the polymer may give rise to a thin barrier with a high probability of tunneling through the barrier.

We report here the improved rectification characteristics of Schottky junctions between p-type (anion-doped) PPy and $\mathrm{Al}$ or In metals. The polymer is electrodeposited from an ambient temperature acetamide-urea-ammonium nitrate eutectic melt. Our earlier results have shown that PPy films prepared from this melt had a more facile 
oxidation and reduction than the one prepared in aqueous solutions. ${ }^{13}$ Another advantage is that the conductivity of the film prepared from the melt is about $10^{-3} \mathrm{ohm}^{-1} \mathrm{~cm}^{-1}$ suitable for junction formation, whereas the value ranged between 10 and $100 \mathrm{ohm}^{-1} \mathrm{~cm}^{-1}$ in the Schottky studies reported on PPy. ${ }^{14,15}$ The dark currentvoltage and capacitance-voltage data are analyzed by applying the thermionic emission theory.

\section{EXPERIMENTAL}

The solvent was a room temperature ternary melt and was prepared as follows. Fifteen grams of vacuum-dried acetamide (Merck, India) was melted at $85^{\circ} \mathrm{C}$ and $10 \mathrm{~g}$ of urea (SD fine) was added to it and stirred well. When the mixture became homogeneous, $8.3 \mathrm{~g}$ of ammonium nitrate (Merck) was added and stirred until the solution was clear. The mixture was cooled to room temperature and used as solvent for electrodeposition. The eutectic mixture was reported to have a density of $1.2 \mathrm{~g} / \mathrm{cm}^{3}$ and a melting point of $7.5^{\circ} \mathrm{C} .^{16}$

Pyrrole was purified by vacuum distillation. PPy films with thickness of about $6.5 \mu \mathrm{m}$ were prepared by anodic oxidation $\left(2 \mathrm{~mA} / \mathrm{cm}^{2}\right)$ of $0.5 \mathrm{M}$ pyrrole from the ternary melt, purged of oxygen with a nitrogen flow prior to electropolymerization. The films were deposited on a gold-coated glass by using $\mathrm{Ag}, \mathrm{AgCl} / \mathrm{Cl}^{-}$(saturated in melt) reference electrode with a platinum foil counter electrode in a single-compartment cell (EG and G PAR, Model 263A Potentiostat/Galvanostat, New York). After polymerization was completed, the films were rinsed in acetonitrile-water mixture to get rid of the monomer and melt and then carefully dried and stored under vacuum. Depositions of $\mathrm{Al}$ and In metal contacts were done by vacuum evaporation. A point mask was used during vacuum deposition and the two metals were evaporated on each of approximately $0.2 \mathrm{~cm}^{2}$. Conductive silver paint was used to take contact leads in the sandwich configuration (Fig. 1). The forward bias corresponds to a negative voltage at metals (front contact) with respect to polymer (back contact). Capacitance-Voltage $(C-V)$ measurements were made using an impedance analyzer (EG and G PAR, Model 6310). The energy band gap was calculated from the absorbance data recorded by using a UV-visible spectrophotometer (Jasco Model 7800).

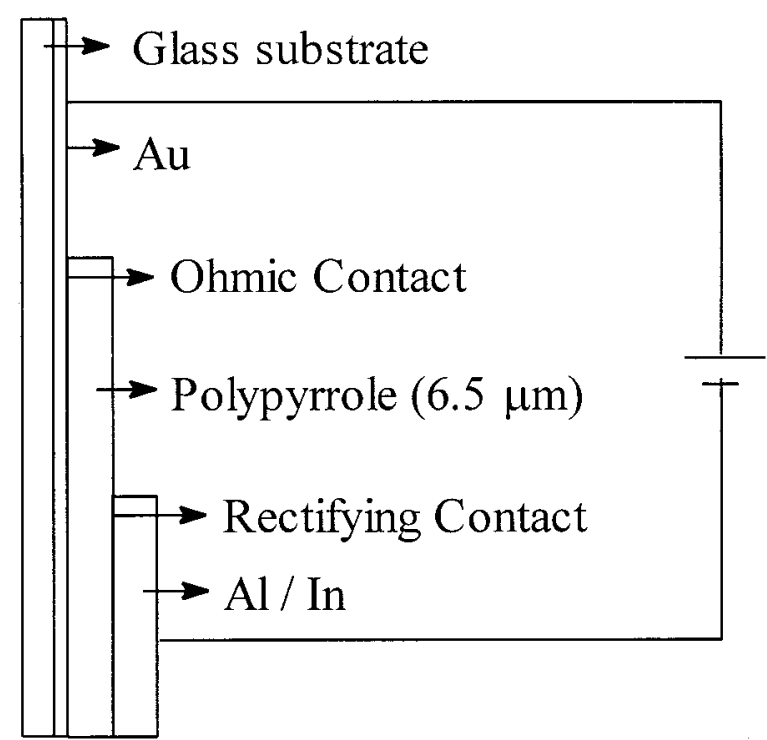

Figure 1 Schematic representation of sandwich configuration of $\mathrm{Au} / \mathrm{p}$-type $\mathrm{PPy} / \mathrm{metal}(\mathrm{Al}$ or $\mathrm{In}$ ) diode.

\section{Theory}

The presence of an optical absorption gap and finite conductivity justify the approximate applicability of band theory to polymeric semiconductors. ${ }^{17}$ When a metal and a polymeric semiconductor (p- or n-type) are brought into contact, a readjustment of charge takes place to establish thermal equilibrium and a potential barrier occurs in the interfacial space charge region (Fig. 2). Three types of junctions can possibly be formed: ohmic contact, which allows free flow of charges from the polymer to metal and vice versa; rectifying contact, which allows only unidirectional flow of charges; and blocking contact, allowing no injection or extraction of charges from the polymer. The potential barrier at the metal-semiconducting polymer contact is determined by the difference in their work functions. It has been established that the metals having a work function greater than that of the polymer make an ohmic contact and the metals with work function less than that of the polymer make an injecting or rectifying junction. ${ }^{17}$

The dark current-voltage $(J-V)$ characteristics of a photovoltaic junction device give information on the quality of the ohmic contact, the rectifying diode behavior, the barrier height, the shunt, and the series resistance that influences the efficiency of the cells. The $J-V$ data can be analyzed by the Schottky relation for thermionic emission. The current density across the junction is given by the equation ${ }^{18}$ : 


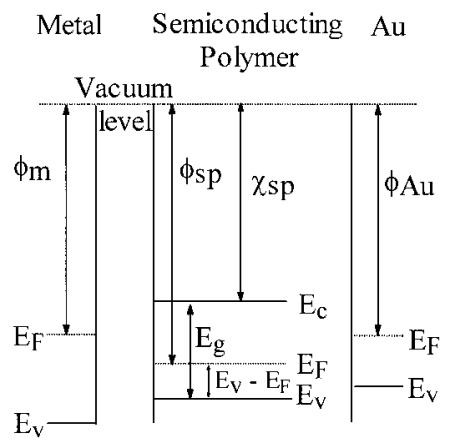

(a)

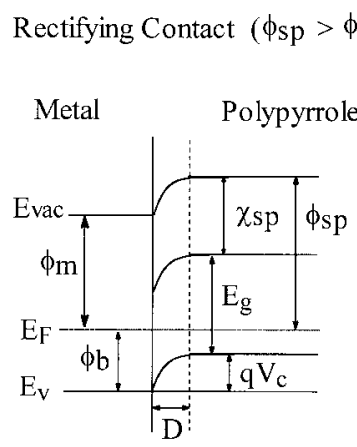

(b)
Ohmic Contact $\left(\phi_{\mathrm{sp}}<\phi_{\mathrm{m}}\right)$

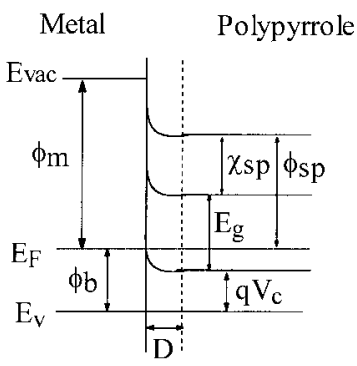

(c)

Figure 2 Energy band diagram of a metal contact to a p-type semiconductor. (a) Before contact, (b) rectifying contact, and (c) ohmic contact. $\phi_{m}$, work function of metal; $\phi_{s p}$, work function of semiconductor polymer film; $\phi_{\mathrm{Au}}$, work function of gold; $q$, electronic charge; $V_{c}$, contact potential; $E_{v}$, valence band; $E_{F}$, Fermi energy level; $E_{c}$, conduction band; $E_{\text {vac }}$, vacuum level; $\phi_{b}$, barrier height; $\chi_{s p}$, electron affinity of the polymeric semiconductor; $E_{g}$, band gap of the polymeric semiconductor; $D$, depletion width.

$$
J=J_{0} \exp (e V / n k T)
$$

where $e$ is the electronic charge, $V$ is the applied voltage, $n$ is the ideality factor, $T$ is the absolute temperature, and $k$ is the Boltzmann constant. The reverse saturation current, $J_{0}$, is given by the equation:

$$
J_{0}=A^{*} T^{2} \exp \left(-e \phi_{b} / k T\right)
$$

where $\phi_{b}$ is the barrier potential and $A^{*}$ is the Richardson constant $\left(120 \mathrm{~A} / \mathrm{k} \mathrm{cm}^{2}\right.$ for a free electron).

The dark capacitance-voltage $(C-V)$ measurements give information about the contact potential and the space charge layer width (or depletion width) of the junction, which play a crucial role in the photovoltaic devices. In the simple Schottky barrier theory, the capacitance $(C)$ can be expressed by the following equation:

$$
C^{-2}=\left[2\left(V_{c}-V\right)\right] /\left(A^{2} e \epsilon \epsilon_{0} N_{s}\right)
$$

here $A$ is the area of the metal contact, $e$ is the electronic charge, $\epsilon$ is the dielectric constant of the polymer, $\epsilon_{0}$ is the free-space permittivity, $N_{s}$ is the carrier concentration, and $V$ is the applied voltage. This equation shows that a plot of $1 / C^{2}$ versus $V$ should give a straight line. The intercept of the line with the voltage abscissa determines the built-in potential or contact potential $V_{c}$ and the slope gives the carrier concentration $N_{s}$, which in turn can be related to carrier mobility $(\mu)$ and depletion width $(D)$ through the following equations:

$$
\sigma=e N_{s} \mu
$$

where $\sigma$ is the electrical conductivity of the $p$ doped polymer, and

$$
D=\left[2 \epsilon \epsilon_{0}\left(V_{c}+V\right) /\left(e N_{s}\right)\right]^{1 / 2}
$$

Although the thermionic emission theory is a good approximation and is generally applied to describe the conduction mechanism in the Schottky diode, we must remember that the determination of various diode parameters is based upon a number of assumptions. In practice, one or more of these assumptions may not be valid. One cannot rule out the participation of other conduction mechanisms such as diffusion, tunneling, PooleFrenkel emission, and space-charge limited current (SCLC) along with Schottky emission. ${ }^{19}$ This is true with the amorphous polymers that are likely to have a distribution of impurity states throughout the forbidden energy band. ${ }^{20}$ In addition to the impurity states, there will be surface trapping centers (surface states) at the metalpolymer interface. It becomes essential to distinguish the surface states from bulk states because space and energy distribution of the two states affect the electrical characteristics in different ways. Forrest et al. ${ }^{21}$ presented a theory for charge transport in organic-on-inorganic semiconductor contact barrier diodes. Their theory 


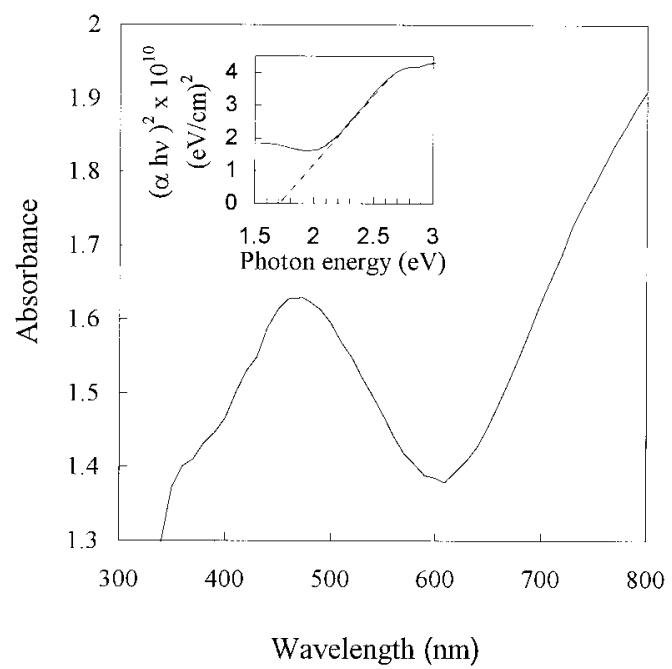

Figure 3 Optical absorption spectrum of doped polypyrrole film coated an indium-tin-oxide substrate. Inset: Curve used for the evaluation of band gap energy $\left(E_{\mathrm{g}}\right)$ of polypyrrole.

predicts that low-voltage transport is limited by thermionic emission of carriers over the energy barrier at the organic-inorganic interface, whereas at high voltage, the current density is determined by space-charge effects. A careful analysis of the dark current-voltage characteristics will be often useful in understanding the role of the above processes in the observed behavior of junctions. ${ }^{17,18}$ For example, when SCLC is dominant, one expects linearity on a plot of $\log J$ versus $\log V$ with a slope of 2 (eq. 6). A plot of $\ln (J / V)$ versus $V^{1 / 2}$ should give a straight line in the case of the Poole-Frenkel emission (eq. 7). Moreover, the temperature dependence of the $J-V$ responses can help to confirm the conduction mechanism:

$$
\begin{gathered}
J=\left[\left(9 \epsilon \epsilon_{0} \mu V^{2}\right) /\left(8 d^{3}\right)\right] \sim V^{2} \\
J / V=(J / V)_{0} \exp \left[\beta(V / d)^{1 / 2} / n k T\right]
\end{gathered}
$$

where $d$ is the thickness of the polymer coating and $\beta=\left(e^{3} / \pi \epsilon \epsilon_{0}\right)^{1 / 2}$.

\section{RESULTS AND DISCUSSION}

Figure 3 shows the absorbance spectrum of PPy coated on an optically transparent indium tin oxide (ITO) substrate. The substrate absorption, if any, was corrected by introducing an uncoated substrate of the same size as the reference. The absorption coefficient $\alpha$ is estimated by using the relation:

$$
\alpha=(2.303 A) / d
$$

where $a$ is the absorbance and $d$ is the thickness of the polymer coating. The relationship between $\alpha$ and the energy band gap is given by ${ }^{22}$

$$
\alpha h \nu \propto\left(h \nu-E_{g}\right)^{1 / 2}
$$

where $E_{g}$ is the energy band gap and $h \nu$ is the radiation energy. A plot of $(\alpha h \nu)^{2}$ versus $h \nu$ gives a straight line, whose intercept on the energy axis is the energy band gap. In the present work, the $E_{g}$ value is estimated to be $1.72 \mathrm{eV}$ (inset in Fig. 3).

Typical dark $J-V$ curves of PPy film with $\mathrm{Al}$ and In metals at room temperature are shown in Figure 4. The characteristics are asymmetrical and show a strongly nonohmic, rectifying behavior. The rectification ratios at $1 \mathrm{~V}$ are 800 and 22 for the junctions with $\mathrm{Al}$ and In, respectively. At a forward bias voltage greater than $0.7 \mathrm{~V}(1.5 \mathrm{~V}$ for In), the current becomes linear, indicating that the device resistance is dominated by polymer bulk resistance.

The next parameters describing the Schottky barrier are the ideality factor $(n)$ and the reverse saturation current $\left(J_{0}\right)$. At a given temperature $\left(25^{\circ} \mathrm{C}\right)$, the ideality factor can be obtained from the slope of the logarithmic plot of $J$ versus $V$ (Fig. 5). Extrapolation of the linear plot to zero bias voltage yields $J_{0}$. The $n$ values are 1.2 and 2.1 and

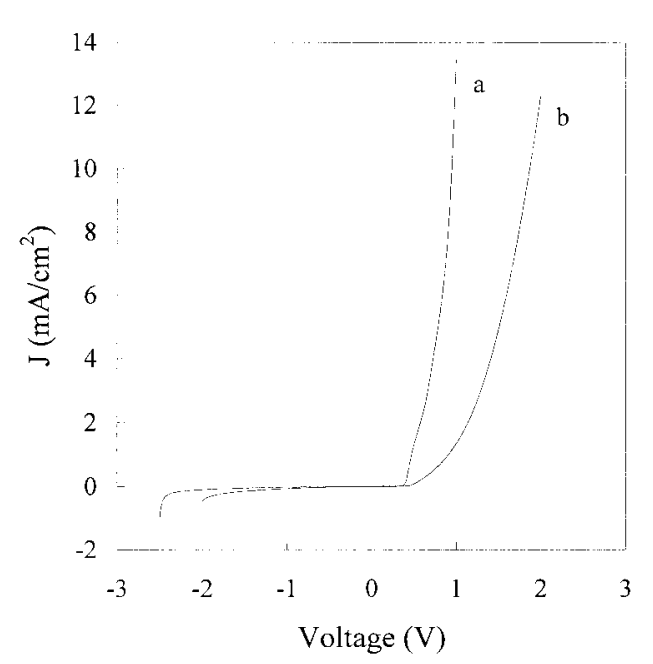

Figure 4 Dark current density versus applied voltage $(J-V$ ) for (a) Au/PPy/Al and (b) Au/PPy/In. 


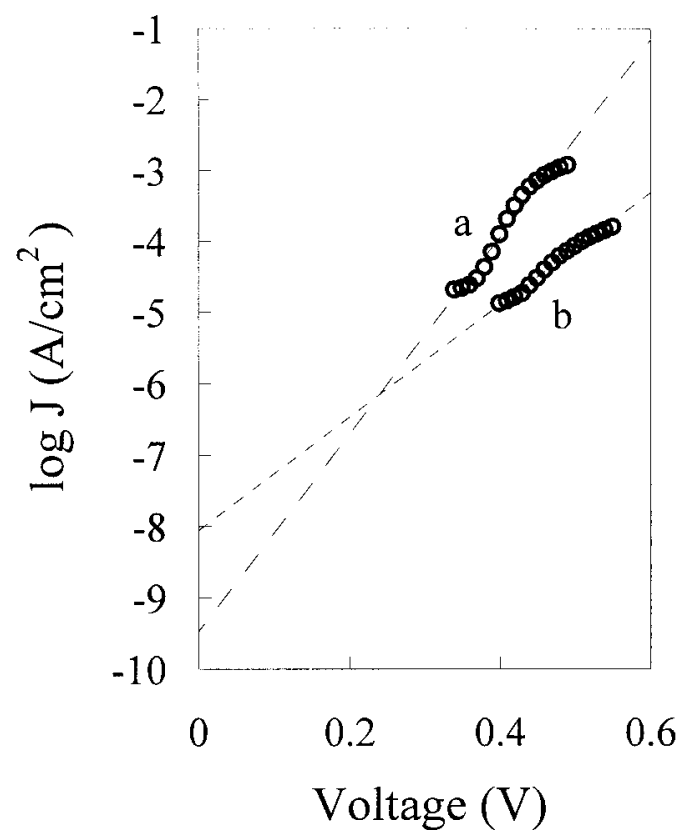

Figure $5 \log J-V$ characteristics of the junctions for (a) $\mathrm{Au} / \mathrm{PPy} / \mathrm{Al}$ and (b) $\mathrm{Au} / \mathrm{PPy} / \mathrm{In}$.

the $J_{0}$ values are $3.2 \times 10^{-10}$ and $8.7 \times 10^{-9}$ $\mathrm{A} / \mathrm{cm}^{2}$ for the junctions with $\mathrm{Al}$ and In, respectively. The corresponding barrier potentials $\left(\phi_{b}\right)$ are 0.97 and $0.89 \mathrm{eV}$.

The $C-V$ characteristics were recorded at various frequencies ranging between $100 \mathrm{~Hz}$ and 100 $\mathrm{kHz}$. Representative plots of $\mathrm{C}^{-2}$ versus applied voltage are shown in Figures 6 and 7. At frequencies lower than $1 \mathrm{kHz}$, the capacitance is found to be varying negligibly with the applied voltage. In

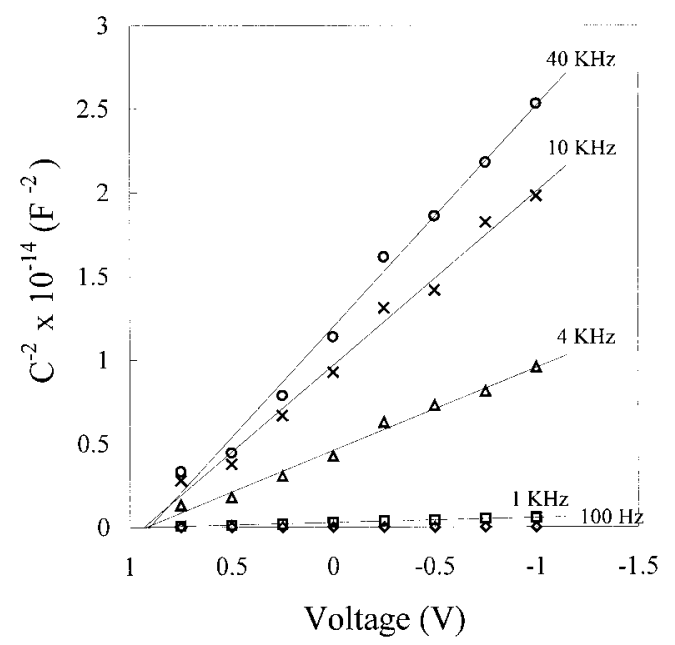

Figure 6 A plot of $C^{-2}$ versus applied voltage for $\mathrm{Au} / \mathrm{PPy} / \mathrm{Al}$.

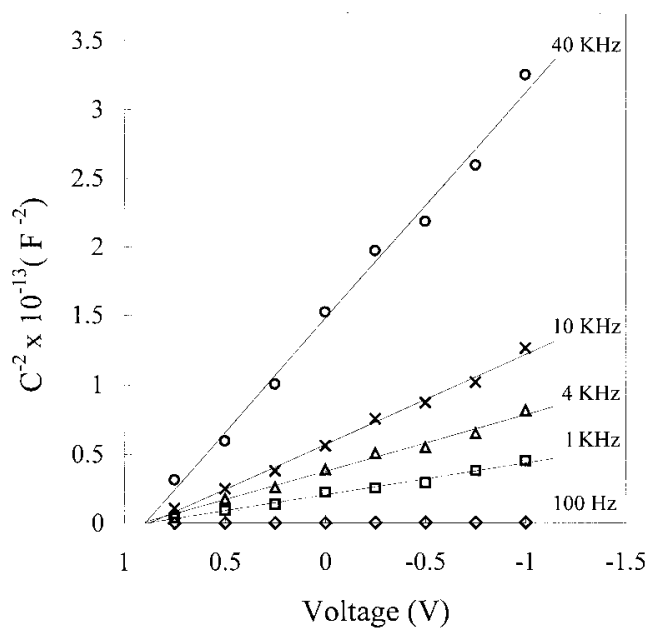

Figure 7 A plot of $C^{-2}$ versus applied voltage for $\mathrm{Au} / \mathrm{PPy} / \mathrm{In}$.

conducting polymers, the measured capacitance will contain contributions from the trap (localized states) filling and emptying process at the depletion layer edge and from any steady-state charge exchange that occurred at traps deep inside the space charge region. Hence, it is necessary to use the lowest possible frequency for the capacitancevoltage measurements because all localized states must respond to the change in the contact potential to be extracted from these $C-V$ curves. ${ }^{5,23}$ The carrier concentration $\left(N_{s}\right)$ values (Table I) reported by various authors for the PPybased Schottky junctions were calculated in the frequency range between $50 \mathrm{~Hz}$ and $10 \mathrm{kHz}$. In the present study, we observe that consistent values for $N_{s}\left(10^{18}\right.$ for $\mathrm{Al}$ and $10^{19}$ for In contact barriers) could be obtained from the $C-V$ data measured in the frequency range between 4 and $40 \mathrm{kHz}$. The linearity of $C^{-2}-V$ plots in this frequency range excludes the possibility of the presence of interface states. ${ }^{24}$ The dielectric constant $(\epsilon)$ of PPy for the calculation of $N_{s}$ was taken to be 13.6. ${ }^{25}$ The contact potentials are 0.91 and $0.87 \mathrm{~V}$ for the junctions with $\mathrm{Al}$ and In, respectively. The work function of PPy can be obtained using the equation ${ }^{17}$ :

$$
\phi_{s p}=q V_{c}+\phi_{m}
$$

where $\phi_{s p}$ and $\phi_{m}$ are the work functions of the semiconducting PPy and metal, respectively. Substituting the values of the work functions of the metals $\left(\phi_{\mathrm{Al}}, 4.25 \mathrm{eV}\right.$ and $\left.\phi_{\mathrm{In}}, 4.12 \mathrm{eV}\right)$, the PPy work function is deduced to be $5.1 \mathrm{eV}$, which is 


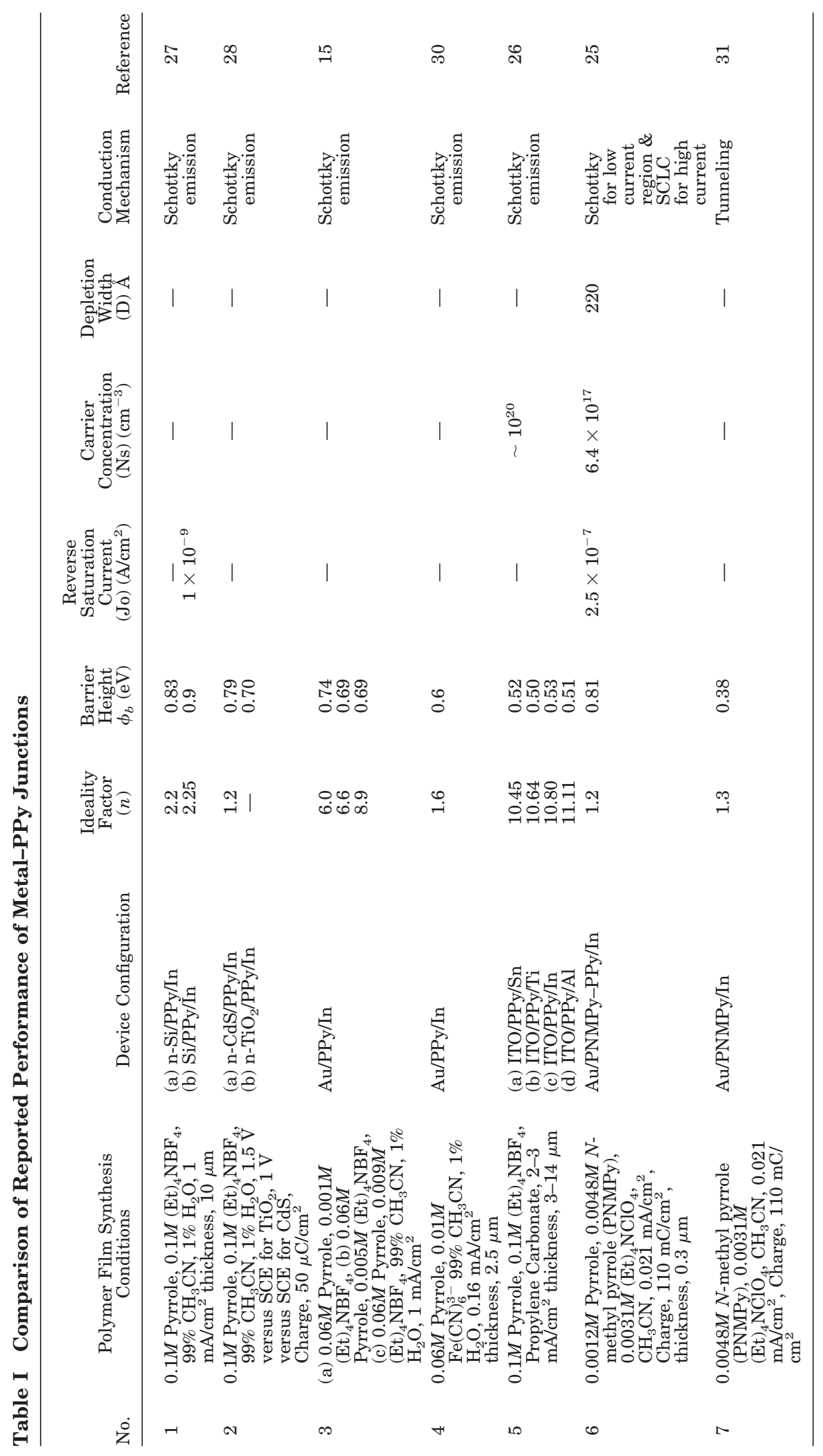




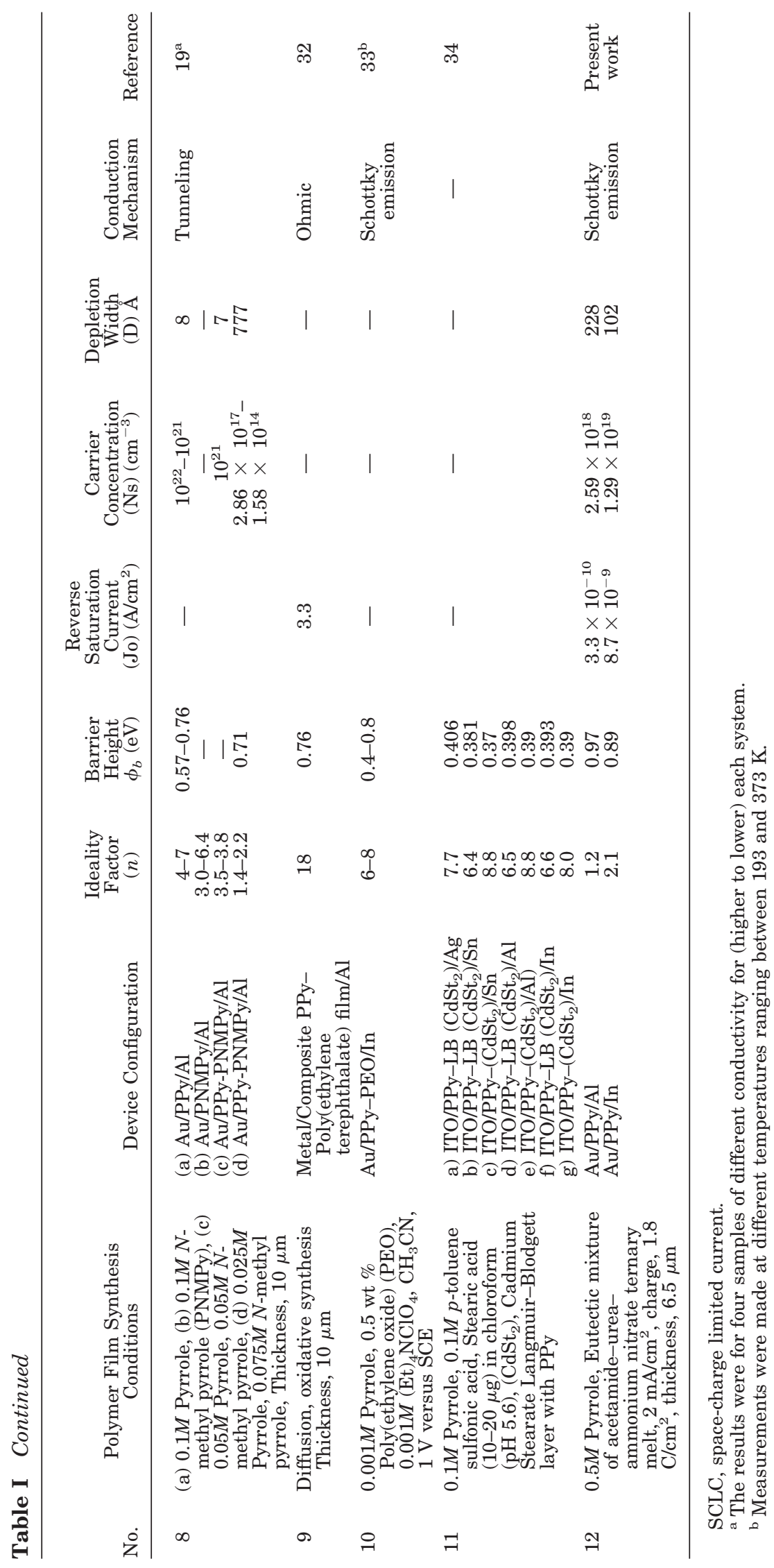


comparable with the value already reported in literature $(4.5 \mathrm{eV}){ }^{26}$

Several studies were reported in literature on the PPy-based Schottky devices. Initial studies have been made by growing PPy films on substrates of single crystals of $\mathrm{n}$-type silicon, $n$-cadmium sulfide, and $n$-titanium dioxide, and also amorphous hydrogenated silicon. ${ }^{27,28}$ The junctions behaved as Schottky barriers on all of these semiconductors and the major objective of that work was the evaluation of the work function of the polymer. It was deduced that the work function of PPy must be close to $5 \mathrm{eV}$. Two types of geometrically different devices, a planar and a sandwich-type, have been studied. ${ }^{29}$ The planar type device showed better rectifying characteristics than the sandwich type. The same authors, in another study, evaluated the junction properties of PPy samples with varying conductivity in the range of $3-70 \mathrm{ohm}^{-1} \mathrm{~cm}^{-1}$ and suggested that samples with conductivity below $20 \mathrm{ohm}^{-1} \mathrm{~cm}^{-1}$ can be used to construct Schottky barriers. ${ }^{15} \mathrm{El}$ Hadri et al. have constructed several junctions of type $\mathrm{Au} / \mathrm{PPy}$-anion/In in sandwich configuration and studied their behavior in both dry and humid atmosphere. ${ }^{30}$ Different anionic dopants such as $\mathrm{BF}_{4}^{-}, \mathrm{ClO}_{4}^{-}, \mathrm{PF}_{6}^{-}$, and $\mathrm{Fe}(\mathrm{CN})_{6}^{3-}$ have been used. The authors concluded that with $\mathrm{BF}_{4}^{-}, \mathrm{ClO}_{4}^{-}$, and $\mathrm{PF}_{6}^{-}$dopants, in dry air, a symmetric nonohmic $J-V$ characteristic led to a tunneling current. However, in humid air, these dopants showed a rectifying property. With $\mathrm{Fe}(\mathrm{CN})_{6}^{3-}$ dopant, a rectifying behavior was obtained in both dry and humid atmosphere.

Metal/PPy junctions have been prepared with electrochemically doped polymer films of different thicknesses. Various metals such as In, Sn, Ti, and $\mathrm{Al}$ were used for junction formation. ${ }^{26}$ The $J-V$ curves showed nonsymmetric behavior for all the cases, although increasing the polymer thickness from 3 to $14 \mu \mathrm{m}$ lowered the current and the breakdown voltage drastically. A Schottky device consisting of the electrochemically prepared copolymer with pyrrole and $N$-methylpyrrole units was constructed with indium metal counter electrode. ${ }^{25}$ This device had the diode quality factor of 1.2 , which was claimed to be one of the excellent Schottky diodes using organic semiconductors. On the basis of the temperature dependence of the $J-V$ characteristics, the authors suggested a tunneling mechanism. ${ }^{31}$ Junction properties of composite films such as PPy-poly(ethylene terepthalate) and $\mathrm{PPy}-$ poly(ethylene oxide) were reported. ${ }^{32,33} \mathrm{PPy}$ was also used to construct met-

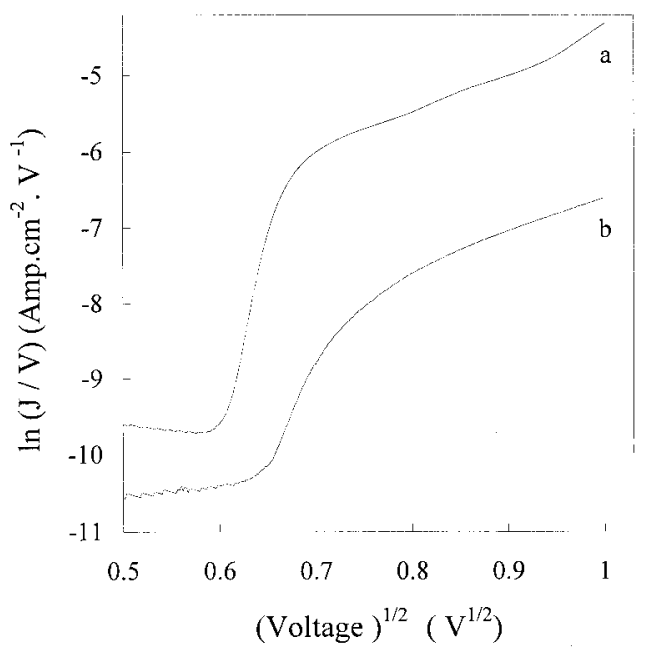

Figure 8 Relationship between $\ln (J / V)$ and $V^{1 / 2}$ (a) $\mathrm{Au} / \mathrm{PPy} / \mathrm{Al}$ and (b) Au/PPy/In.

al-insulator-semiconductor (MIS) ${ }^{34}$ and metalinsulator-metal (MIM) $)^{35}$ devices and the junction parameters have been estimated.

In Table I, the junction parameters reported by various authors for the PPy-based Schottky devices are compiled along with the results obtained in the present work. It is noted that only four studies have reported an ideality factor close to unity. However, only in one report by Koezuka and Etoh on the PPY-PNMPy copolymer-based Schotty diode, a complete estimation of all the diode parameters was made. ${ }^{25}$ However, in that study, the copolymer needed a heat treatment at $80^{\circ} \mathrm{C}$ for $8 \mathrm{~h}$ in air. This was necessary to stabilize the electrical characteristics of the device before the deposition of a blocking electrode. Further, in that device, the current was controlled by Schottky-type barrier only for the low-current region, whereas a space-charge injection was operative beyond the flat band state. These authors have confirmed the presence of a thin oxide layer on the polymer surface from their impedance studies. In another report which has quoted an ideality factor of 1.3 for the $\operatorname{poly}\left(N\right.$-methyl pyrrole)-based diode ${ }^{31}$ a tunneling mechanism was proven from temperature studies. A comparison of the reported values for the various parameters with the present data indicates superiority of the present method used for the polymer film formation from the organic melt for the diode construction. Further analysis of the $J-V$ data (Fig. 8) confirm the Schottky emission as the dominant conduction mechanism. 


\section{CONCLUSION}

We have shown that Schottky diodes fabricated with the semiconducting PPy prepared from the room-temperature acetamide-urea-ammonium nitrate eutectic melt resulted in improved junction parameters. In particular, the diode formed with $\mathrm{Al}$ metal showed better values for the ideality factor, rectification ratio, and breakdown voltage. It is interesting that the $J-V$ curves of this device when recorded even after a lapse of 3 months showed very little difference from its first set of data, indicating good stability. Further experiments are necessary to study the effects of temperature and illumination for improvement of device performance.

P. S. Abthagir is grateful to the Council of Scientific and Industrial Research, New Delhi for the award of a Senior Research Fellowship.

\section{REFERENCES}

1. Tanikawa, K.; Okuno, Z.; Iwaoka, T.; Hatano, M. J Appl Phys 1977, 48, 2424.

2. Burroughes, J. H.; Jones, C. A.; Friend, R. H. Nature 1988, 355, 137.

3. Burroughes, J. H.; Jones, C. A.; Friend, R. H. Synth Met 1989, 28, C735.

4. Hovel, H. J. Semiconductors and Semimetals, Vol. 2, Solar Cells; Academic Press: New York, 1975.

5. Kanicki, J. Mol Cryst Liq Cryst 1984, 105, 203.

6. Grant, P. M.; Tani, T.; Gill, W. D.; Krounbi, M.; Clarke, T. C. J Appl Physiol 1981, 52, 869.

7. Turut, A.; Koleli, F. J Appl Phys 1992, 72, 818.

8. Nazarova, I. B.; Krinichnyi, V. I.;. Goldenberg, L. M. Synth Met 1993, 53, 399.

9. Misra, S. C. K.; Chandra, S. Indian J Chem 1994, $33 \mathrm{~A}, 583$.

10. Chen, S. A.; Fang, Y.; Lee, H. T. Synth Met 1993, 55-57, 4082 .

11. Misra, S. C. K.; Ram, M. K.; Pandey, S. S.; Malhotra, B. D.; Chandra, S. Appl Phys Lett 1992, 61, 1219 .
12. Ram, M. K.; Sundaresan, N. S.; Malhotra, B. D. J Phys Chem 1993, 97, 1158.

13. Dhanalakshmi, K.; Saraswathi, R.; Srinivasan, C. Synth Met 1996, 82, 237.

14. Kanazawa, K. K.; Diaz, A. F.; Gill, W. D.; Grant, P. M.; Street, G. B.; Gardini, G. P.; Kwak, J. F. Synth Met 1979/80, 1, 329.

15. Miyauchi, S.; Fueki, A.; Sorimachi, Y.; Tsubata, I. Synth Met 1989, 28, C691.

16. Sampath, S.; Narayan, R. J Electrochem Soc 1991, 138, 2267.

17. Kancki, J. Handbook of Conducting Polymers; T. A. Skotheim, Ed.; Marcel Dekker: New York, 1986.

18. Sze, S. M. Physics of Semiconductor Devices; Wiley: New York, 1969.

19. Singh, R.; Narula, A. K. Appl Phys Lett 1997, 71, 2845.

20. Gupta, H. M. Phys Status Solids A 1997, 164, 733.

21. Forrest, S. R.; Kaplan, M. L.; Schmidt, P. H. J Appl Phys 1984, 55, 1492.

22. Yeh, T. H.; Blakeslee, A. E. J Electrochem Soc 1963, 110, 1018.

23. Goodman, A. M. J Appl Phys 1963, 34, 329.

24. Turut, A.; Yalcin, N.; Saglam, M. Solid State Electron 1992, 35, 835.

25. Koezuka, H.; Etoh, S. J Appl Phys 1983, 54, 2511.

26. Gupta, R.; Misra, S. C. K.; Malhotra, B. D.; Beladakere, N. N.; Chandra, S. Appl Phys Lett 1991, 58, 51.

27. Inganas, O.; Skotheim, T.; Lundstrom, I. Physica Scripta 1982, 25, 863.

28. Inganas, O.; Skotheim, T.; Lundstrom, I. J Appl Phys 1983, 54, 3636.

29. Miyauchi, S.; Fueki, A.; Kushihi, Y.; Abiko, H.; Sorimachi, Y. Synth Met 1987, 18, 689.

30. El Hadri, A.; Maleysson, C.; Robert, H. Synth Met 1989, 28, C697.

31. Kurata, T.; Koezuka, H.; Tsunoda, S.; Ando, T. J Phys D: Appl Phys1986, 19, L57.

32. Li, C.; Song, Z. Synth Met1991, 44, 159.

33. Miyauchi, S.; Hattori, Y.; Takamatsu, T.; Sorimachi, Y. J Appl Polym Sci 1992, 44, 377.

34. Ram, M. K.; Annapoorni, S.; Malhotra, B. D. J Appl Polym Sci 1996, 60, 407.

35. Osaka, T.; Fukuda, T.; Ouchi, K.; Momma, T. Thin Solid Films 1992, 215, 200. 